\title{
JARINGAN SARAF TIRUAN UNTUK MEMPREDIKSI TINGKAT PEMAHAMAN SISIWA TERHADAP MATAPELAJARAN DENGAN MENGGUNAKAN ALGORITMA BACKPROPAGATION
}

\author{
Solikhun, M. Safii, Agus Trisno \\ Program Studi Manajemen Informatika, AMIK Tunas Bangsa Pematangsiantar \\ Program Studi Sistem Informasi, STIKOM Tunas Bangsa Pematangsiantar \\ Jln. Jenderal Sudirman Blok A No. 1,2,3 Pematangsiantar \\ solikhun@amiktunasbangsa.ac.id, m.safii@amiktunasbangsa.ac.id, a.trins@yahoo.com
}

\begin{abstract}
Prediction of students 'understanding of the subject is important to know the extent to which the students' understanding of the subjects presented by educators when teaching and learning activities and to determine the ability of educators in delivering subjects. Artificial Neural Network to predict the level of students' understanding of subjects using backpropagation learning algorithm uses several variables: Knowledge, skills / abilities, assessment and workload and guidance and counseling. Backpropagation learning algorithm is applied to train eight indicators to predict the level of students' understanding of the subjects. The test results obtained by the student's understanding level prediction accuracy rate of $90 \%$ with a 6-5-1 architecture.
\end{abstract}

Keywords: Neural Networks, Backpropagation, Prediction Comprehension Level Students

\begin{abstract}
Abstrak
Prediksi tingkat pemahaman siswa terhadap mata pelajaran sangatlah penting untuk mengetahui sampai dimana pemahaman siswa terhadap mata pelajaran yang disampaikan oleh pendidik pada saat kegiatan belajar mengajar dan untuk mengetahui kemampuan pendidik dalam menyampaikan mata pelajaran. Artificial Neural Network untuk memprediksi tingkat pemahaman siswa terhadap mata pelajaran menggunakan algoritma pembelajaran backpropagation menggunakan beberapa variabel yaitu: Pengetahuan, ketrampilan/kemampuan, penilaian \& beban kerja dan bimbingan \& konseling. Algoritma pembelajaran Backpropagation diterapkan untuk melatih delapan variabel tersebut untuk memprediksi tingkat pemahaman mahasiswa terhadap mata pelajaran. Hasil pengujian diperoleh prediksi tingkat pemahaman siswa dengan tingkat akurasi $90 \%$ dengan arsitektur 4-2-1.
\end{abstract}

Kata kunci : Jaringan Saraf Tiruan, Backpropagation, Tingkat Pemahaman Siswa

\section{PENDAHULUAN}

Jaringan saraf tiruan (JST) (artificial neural network (ANN) / simulated neural network (SNN) / neural network(NN)) adalah jaringan yang terdiri atas sekelompok unit pemroses kecil yang dimodelkan berdasarkan jaringan saraf 
manusia. (Sari Indah Anatta Setiawan, 2011). Jaringan saraf tiruan adalah paradigma pemrosesan suatu informasi yang terinspirasi oleh sistem sel saraf bilogin sama seperti otak yang memproses suatu informasi[1].

Jaringan saraf tiruan sama seperti halnya manusia yang belajar dari suatu contoh untuk memecahkan suatu masalah yang memiliki pola yang sama dengan contoh yang diberikan. Jaringan Syaraf Tiruan (JST) merupakan suatu sistem pemrosesan informasi yang mempunyai karakteristik menyerupai jaringan syaraf biologis (JSB) Jaringan Syaraf Tiruan tercipta sebagai suatu generalisasi model matematis dari pemahaman manusia (human cognition) [2].

Proses belajar mengajar merupakan salah satu kegiatan dalam sebuah sekolah dalam mencerdaskan kehidupan bangsa. Peran tersebut tidak terlepas dari tenaga pengajar professional dan pamahaman siswa yang baik. Dalam proses belajar mengajar perlunya hubungan dua arah antara siswa dan tenaga pengajar. Ini dimaksudkan supaya ada kerjasama yang baik selama proses belajar mengajar berlangsung. Analisa yang dilakukan oleh pihak sekolah terhadap proses belajar mengajar sangat perlu dilakukan diakhir semester. Ini bertujuan agar ada penilaian terhadap siswa dan tenaga pengajar professional. Bagi siswa ini bertujuan menilai tingkat pemahaman dan daya serap terhadap mata pelajaran yang diajarkan dan bagi tenaga pengajar professional ini bertujuan untuk menilai sejauh mana tenaga pengajar professional dapat menyalurkan pengetahuanya terhadap mata pelajaran yang diampunya selama 1 (satu) semester. Sehingga pihak sekolah dapat memberikan keputusan yang adil. Dalam memprediksi sampai mana tingkat pemahaman siswa terhadap matapelajaran.

Dari uraian diatas penulis melakukan penelitian dengan judul jaringan saraf tiruan untuk memprediksi tingkat pemahaman siswa terhadap mata pelajaran dengan menggunakan algoritma backpropagation.

\section{METODE PENELITIAN}

\subsection{Kecerdasan Buatan (Artificial Intellegence)}

Kecerdasan Buatan (Artificial Intelligence atau AI) didefinisikan sebagai kecerdasan yang ditunjukkan oleh suatu entitas buatan. Sistem seperti ini umumnya dianggap komputer. Kecerdasan diciptakan dan dimasukkan ke dalam suatu mesin (komputer) agar dapat melakukan pekerjaan seperti yang dapat dilakukan manusia. Kecerdasan Buatan (Artificial Intelligence atau AI) didefinisikan sebagai kecerdasan yang ditunjukkan oleh suatu entitas buatan. Sistem seperti ini umumnya dianggap komputer. Kecerdasan diciptakan dan dimasukkan ke dalam suatu mesin (komputer) agar dapat melakukan pekerjaan seperti yang dapat dilakukan manusia. AI adalah bidang studi berdasarkan pada premis bahwa pikiran cerdas dapat dianggap sebagai bentuk perhitungan [3].

\subsubsection{Definisi kecerdasan Buatan}

Kecerdasan buatan (Artificial Intelegent) merupakan salah satu bagian dari ilmu komputer yang memperlajari bagaimana membuat mesin komputer dapat melakukan pekerjaan seperti dan sebaik yang dilakukan oleh manusia bahkan bisa lebih baik daripada yang dilakukan manusia. Menurut John McCarthy dalam Dahria (2008), Artificial Intelegent (AI) adalah untuk mengetahui dan memodelkan proses-proses berpikir manusia dan mendesain mesin agar dapat menirukan 
perilaku manusia. Cerdas, berarti memiliki pengetahuan dan pengalaman, Penalaran, bagaimana membuat keputusan dan mengambil tindakan moral yang baik[4].

\subsubsection{Soft Computing}

Soft Computing merupakan inovasi baru dalam membangun sistem cerdas yaitu sistem yang memiliki keahlian seperti manusia pada domain tertentu, mampu beradaptasi dan belajar agar dapat bekerja lebih baik jika terjadi perubahan lingkungan. Soft Computing mengekploitasiadanya toleransi terhadap ketidaktepatan, ketidakpastian dan kebenaran parsial untuk dapat diselesaikan dan dikendalikan dengan mudah agar sesuai dengan realita (Zadeh dalam Dahria, 2008). Metodologi-metodologi yang digunakan dalam soft computing adalah :

1. Sistem Fuzzy (Mengakomodasi ketidaktepatan) Logika Fuzzy (fuzzy logic).

2. Jaringan Saraf Tiruan (Neural Network).

3. Probabilistic Reasoning (Mengakomodasi ketidakpastian).

4. Evolutionary Computing (Optimasi) Algoritma Genetika[4]..

\subsection{Jaringan Saraf Tiruan (Artificial Neural Network)}

Jaringan syaraf tiruan (JST) adalah paradigm pemrosesan suatu informasi yang terinspirasi oleh sistem sel syaraf biologi. Jaringan ini biasanya diimplementasikan dengan menggunakan komponen elektronik atau disimulasikan pada aplikasi computer[5].

\subsection{Model Neuron}

Menurut Haykin (2012), neuron adalah unit pengolah informasi yang merupakan dasar dari proses sebuah Jaringan Saraf Tiruan. Dijelaskan juga ada tiga elemen dasar dari model saraf yaitu:

1. Satu set dari sinapsis, atau penghubung yang masing-masing digolongkan oleh bobot atau kekuatannya.

2. Sebuah penambah untuk menjumlahkan sinyal-sinyal input. Ditimbang dari kekuatan sinaptik masing-masing neuron.

3. Sebuah fungsi aktivasi untuk membatasi amplitudo output dari neuron. Fungsi ini bertujuan membatasi jarak amplitude yang diperbolehkan oleh sinyal output menjadi sebuah angka yang terbatas[6].

\subsection{Algoritma Backpropagation}

Algoritma Backpropagation untuk melakukan training terhadap suatu jaringan terdiri dari tiga tahap, yaitu feedforward dari pola input training, backpropagation dari error yang terkait, dan penyesuaian bobot.

Langkah-langkah dalam algoritma backpropagation oleh Fausett (1994) adalah sebagai berikut:

Langkah 0: Inisialisasi bobot (set bobot pada nilai random yang kecil).

Langkah 1: Ketika pada kondisi berhenti salah, lakukan langkah 2 - 9.

Langkah 2: $\quad$ Untuk setiap pasangan training, lakukan langkah 3-8.

\section{Feedforward}


Langkah 3: $\quad$ Setiap unit input $\left(X_{i}, i=1, \ldots, n\right)$ menerima sinyal input $\mathrm{X}_{\mathrm{i}}$ dan memancarkan sinyal ini kepada semua unit pada lapisan diatasnya (hidden unit)

Langkah 4: $\quad$ Setiap hidden unit $\left(Z_{j, j}=1, \ldots, p\right)$ menjumlahkan bobot sinyal input.

$z_{-} i n_{j}=V_{0 j}+\sum_{i=1}^{n} X_{i} V_{i j}$

mengaplikasikan fungsi aktivasi untuk menghitung sinyal output

$z_{j}=f\left(z_{-} i n_{j}\right)$

dan mengirim sinyal ke semua unit di lapisan di atasnya (output unit).

Langkah 5: $\quad$ Setiap unit output $\left(Y_{k}, k=1, \ldots, m\right)$ menjumlahkan bobot sinyal input.

$y_{-} i_{k}=W_{0 k}+\sum_{j=1}^{p} Z_{j} W_{j k}$

dan mengaplikasikan fungsi aktivasinya untuk menghitung sinyal output.

$y_{k}=f\left(y_{-} i n_{k}\right)$

\section{Backpropagation}

Langkah 6: Setiap unit output $\left(Y_{k}, k=1, \ldots, m\right)$ menerima pola target sesuai dengan pola training input, menghitung informasi error.

$\delta_{k}=\left(t_{k}-y_{k}\right) f^{\prime}\left(y_{-} i n_{k}\right)$

menghitung koreksi bobotnya (digunakan untuk memperbaharui $\mathrm{w}_{\mathrm{jk}}$ )

$\Delta w_{j k}=\alpha \delta_{k} z_{j}$

menghitung koreksi bias (digunakan untuk memperbaharui W0k)

$\Delta w_{0 k}=\alpha \delta_{k}$

mengirim $\delta_{k}$ ke unit lapisan dibawahnya

Langkah 7: $\quad$ Setiap hidden unit $\left(Z_{j}, j=1, \ldots, p\right)$ menjumlahkan delta input (dari unit di lapisan atas).

$\delta \_i n_{j}=\sum_{k=1}^{m} \delta_{k} W_{j k}$

dikalikan dengan turunan dari fungsi aktivasi untuk menghitung informasi error.

$$
\delta_{j}=\delta_{-} i n_{j} f^{\prime}\left(z_{-} i n_{j}\right)
$$

menghitung koreksi bobot (digunakan untuk memperbaharui $\mathrm{V}_{\mathrm{ij}}$ )

$$
\Delta v_{i j}=\alpha \delta_{j} x_{i}
$$




\section{Update bobot dan bias}

dan menghitung koreksi bias (digunakan untuk memperbaharui $\mathrm{v}_{0 \mathrm{j}}$ )

$$
\Delta v_{0 j}=\alpha \delta_{j}
$$

Langkah 8: Setiap unit output $\left(Y_{k}, k=1, \ldots, m\right)$ memperbaharui bias dan bobot $(\mathrm{j}=0, \ldots, \mathrm{p})$

$w_{j k}($ baru $)=w_{j k}($ lama $)+\Delta w_{j k}$

Setiap hidden unit $\left(Z_{j}, j=1, \ldots, p\right)$ memperbaharui bobot dan bias $(i=0, \ldots, n)$

$v_{i j}($ baru $)=v_{i j}($ lama $)+\Delta v_{i j}$

Langkah 9: Tes kondisi berhenti.

\section{Algoritma aplikasi}

Setelah training, jaringan saraf backpropagation diaplikasikan dengan hanya menggunakan fase feedforward dari algoritma training. Langkahlangkahnya sebagai berikut oleh Fausett (1994):

Langkah 0: Inisialisasi bobot (dari algoritma training).

Langkah 1: Untuk setiap vektor input lakukan langkah 2-4.

Langkah 2: $\quad$ Untuk $i=1, \ldots, n$ set aktivasi untuk unit input $\mathrm{x}_{\mathrm{i}}$.

\section{Feedforward}

Langkah 3: $\quad$ Untuk setiap $j=1, \ldots, p$

$$
\begin{array}{r}
z_{-} i n_{j}=V_{0 j}+\sum_{i=1}^{n} X_{i} V_{i j} \\
z_{j}=f\left(z_{-} i n_{j}\right)
\end{array}
$$

Langkah 4: Untuk setiap $k=1, \ldots, m$

$$
\begin{aligned}
& y_{-} i n_{k}=W_{0 k}+\sum_{j=1}^{p} Z_{j} W_{j k} \\
& y_{k}=f\left(y_{-} i n_{k}\right)
\end{aligned}
$$

\section{HASIL DAN PEMBAHASAN}

\subsection{Perancangan Sistem}

\subsubsection{Pendefinisian Input dan Target}

Data siswa selanjutnya akan diolah oleh Jaringan Saraf Tiruan dengan metode backpropogation. Agar data dapat dikenali oleh Jaringan Saraf Tiruan, maka data harus direpresentasikan ke dalam bentuk numerik antara 0 sampai dengan 1 , baik variabel maupun isinya yang merupakan masukan data siswa pada 
SMK Prama Artha Simalungun sebagai pengenalan pola dan keluaran yang merupakan prediksi pemahaman siswa yang diperoleh dari model arsitektur terbaik pada saat penentuan pola terbaik. Hal ini dikarenakan jaringan menggunakan fungsi aktivasi sigmoid biner (logsig) yang rangenya dari 0 sampai 1. Nilai-nilai yang digunakan diperoleh berdasarkan kategori dari masing-masing variabel selain juga untuk memudahkan mengingat dalam pendefinisiannya.

\subsubsection{Pendefinisian Input}

Variabel penentuan tingkat pemahaman siswa merupakan kriteria yang menjadi acuan dalam pengambilan keputusan pada penilaian dengan menggunakan Jaringan Saraf Tiruan. Variabel ditentukan dengan cara melihat ketergantungan data terhadap penelitian yang dilakukan. Adapun daftar variabel dalam penentuan pemahaman siswa terhadap mata pelajaran yaitu tertera pada tabel 1 :

Tabel 1 : Daftar Kriteria dalam Pemahaman Siswa terhadap Mata pelajaran

\begin{tabular}{|c|c|c|c|c|c|}
\hline No & Kriteria & Variabel & $\begin{array}{c}\text { Rank Rata- } \\
\text { Rata Nilai }\end{array}$ & Keterangan & Berat \\
\hline \multirow{5}{*}{1} & \multirow{5}{*}{ Pengetahuan } & \multirow{5}{*}{ A } & 5 & Sangat Setuju & 1 \\
\hline & & & $4-4,99$ & Setuju & 0.8 \\
\hline & & & $3-3,99$ & Sedang & 0.6 \\
\hline & & & $2-2,99$ & Tidak Setuju & 0.4 \\
\hline & & & $0-1,99$ & Sangat Tidak Setuju & 0.2 \\
\hline \multirow{5}{*}{2} & \multirow{5}{*}{$\begin{array}{l}\text { Keterampilan / } \\
\text { Kemampuan }\end{array}$} & \multirow{6}{*}{ B } & 5 & Sangat Setuju & 1 \\
\hline & & & $4-4,99$ & Setuju & 0.8 \\
\hline & & & $3-3,99$ & Sedang & 0.6 \\
\hline & & & $2-2,99$ & Tidak Setuju & 0.4 \\
\hline & & & $0-1,99$ & Sangat Tidak Setuju & 0.2 \\
\hline \multirow{5}{*}{3} & \multirow{5}{*}{$\begin{array}{c}\text { Penilaian Dan } \\
\text { Beban Kerja }\end{array}$} & & 5 & Sangat Setuju & 1 \\
\hline & & \multirow{4}{*}{$\mathrm{C}$} & $4-4,99$ & Setuju & 0.8 \\
\hline & & & $3-3,99$ & Sedang & 0.6 \\
\hline & & & $2-2,99$ & Tidak Setuju & 0.4 \\
\hline & & & $0-1,99$ & Sangat Tidak Setuju & 0.2 \\
\hline \multirow{5}{*}{4} & \multirow{5}{*}{$\begin{array}{l}\text { Bimbingan dan } \\
\text { konseling }\end{array}$} & \multirow{5}{*}{$\mathrm{D}$} & 5 & Sangat Setuju & 1 \\
\hline & & & $4-4,99$ & Setuju & 0.8 \\
\hline & & & $3-3,99$ & Sedang & 0.6 \\
\hline & & & $2-2,99$ & Tidak Setuju & 0.4 \\
\hline & & & $0-1,99$ & Sangat Tidak Setuju & 0.2 \\
\hline
\end{tabular}

Sumber : Data Olahan

Data input diperoleh dari kuisioner yang diberikan kepada siswa SMK Swasta Prama Artha Simalungun. Dari kuisioner tersebut diperoleh informasi tentang data siswa yang sudah mengikuti proses belajar selama semester 1 dan 2 tahun ajaran 2015/2016.

Data sampel siswa SMK Swasta Prama Artha Simalungun semester 1 dan 2 tahun pelajaran 2015/2016 yang terdiri dari 40 data dan masing masing data 
memiliki 4 variabel dan 1 target. Data ini nantinya akan ditransformasikan ke sebuah data antara 0 sampai 1 sebelum dilakukan pelatihan dan pengujian menggunakan Jaringan Saraf Tiruan metode backpropagation.

\subsubsection{Pendefinisian Target}

Adapun data target adalah 1 yaitu siswa memahami mata pelajaran.

\subsection{Pengolahan Data}

Pengolahan data dilakukan dengan bantuan Matlab 6.1 aplikasi perangkat lunak. Sampel Data baku 40 siswa akan dibagi menjadi dua bagian, yaitu data pelatihan dan data pengujian. Data mentah akan dikonversi berubah menjadi tabel kriteria yang telah ditentukan pada Tabel 1. Sedangkan untuk sampel data yang telah diproses dan ditranformasikan adalah sebagai berikut.

Tabel 2: Sampel dari data yang telah ditransformasikan

\begin{tabular}{cclcccccc}
\hline \multirow{2}{*}{ NO } & \multirow{2}{*}{ NIS } & \multirow{2}{*}{ NAMA } & \multicolumn{3}{c}{ VARIABEL INPUT } & \multirow{2}{*}{ TARGET } \\
& & & $\mathrm{A}$ & $\mathrm{B}$ & $\mathrm{C}$ & $\mathrm{D}$ & \\
\hline & & X1 & $\mathrm{X} 2$ & $\mathrm{X} 3$ & $\mathrm{X} 4$ & $\mathrm{X} 5$ \\
1 & 1514 & ADE IRMA CITA DEWI & 0.8 & 0.6 & 0.6 & 0.8 & 1 \\
2 & 1517 & ANDI KUSUMA & 0.8 & 1 & 0.8 & 0.8 & 1 \\
3 & 1518 & ANDREANSYAH & 0.8 & 0.6 & 0.4 & 0.4 & 1 \\
4 & 1519 & ANJAS SULISTIAWAN & 0.8 & 0.8 & 0.8 & 1 & 1 \\
5 & 1520 & APRIL FRANCIS TAMPUBOLON & 0.6 & 0.6 & 0.8 & 0.6 & 1 \\
6 & 1522 & ARYA DWI SUMANTHA SIDAURU & 0.8 & 0.8 & 0.8 & 0.8 & 1 \\
7 & 1523 & ARYA SUKMA JAYA WARDANA & 0.6 & 0.8 & 0.6 & 0.8 & 1 \\
8 & 1524 & DEVI GUSTIADANI PARANGIN-ANGIN & 0.8 & 0.6 & 0.6 & 0.8 & 1 \\
9 & 1526 & DICKY WAHYUDI & 0.8 & 0.8 & 0.6 & 0.8 & 1 \\
10 & 1527 & DWI SHAFIRA BATUBARA & 0.6 & 0.8 & 0.6 & 0.6 & 1 \\
11 & 1528 & EDI KURNIAWAN & 0.8 & 0.8 & 0.6 & 0.8 & 1 \\
12 & 1529 & FAISAL & 0.6 & 0.4 & 0.6 & 0.8 & 1 \\
13 & 1530 & FARADILA HAFIZAH PARINDURI & 0.8 & 0.8 & 1 & 1 & 1 \\
14 & 1532 & ILLIAS & 0.6 & 0.6 & 0.8 & 0.6 & 1 \\
15 & 1533 & INDAH DESWITA & 0.8 & 1 & 0.8 & 0.8 & 1 \\
16 & 1534 & JENI ARISKA & 0.8 & 0.8 & 0.8 & 0.8 & 1 \\
17 & 1536 & LISNA WATI & 0.8 & 0.8 & 0.6 & 0.8 & 1 \\
18 & 1537 & MILO SANDIKA & 0.8 & 0.6 & 0.8 & 1 & 1 \\
19 & 1538 & MONICA APRILLIA DAMANIK & 0.8 & 0.8 & 0.8 & 0.8 & 1 \\
20 & 1539 & MUHAMMAD BAYU SHOPAN & 0.8 & 0.6 & 0.8 & 0.6 & 1 \\
21 & 1542 & NIA BAZHLINA & 0.8 & 0.8 & 0.6 & 0.8 & 1 \\
22 & 1544 & PANCA IRAWAN & 0.6 & 0.6 & 0.8 & 0.6 & 1 \\
23 & 1545 & PUTRA PANDU KHAIRUN NAZRI & 0.6 & 0.4 & 0.6 & 0.8 & 1 \\
24 & 1546 & PUTRI MAYANG SARI & 0.6 & 0.8 & 0.8 & 0.8 & 1 \\
25 & 1547 & RAHMAD & 0.6 & 0.6 & 0.8 & 0.8 & 1 \\
26 & 1548 & RAMA DONA & 0.6 & 0.8 & 0.8 & 0.8 & 1 \\
& & & & & & &
\end{tabular}




\begin{tabular}{lllccccc}
\hline \multirow{2}{*}{ NO } & \multirow{2}{*}{ NIS } & \multirow{2}{*}{ NAMA } & \multicolumn{8}{c}{ VARIABEL INPUT } & \multirow{2}{*}{ TARGET } \\
& & & $\mathrm{A}$ & $\mathrm{B}$ & $\mathrm{C}$ & $\mathrm{D}$ & \\
\hline 27 & 1549 & RIDUAN SANTOSO & 0.6 & 0.4 & 0.6 & 1 & 1 \\
28 & 1550 & RIKA WARDANI & 0.8 & 0.6 & 0.8 & 1 & 1 \\
29 & 1551 & RIZKY SYAHPUTRA & 0.6 & 0.6 & 0.6 & 0.8 & 1 \\
30 & 1552 & RONI SANJAYA HASUGIAN & 0.6 & 0.6 & 0.4 & 0.6 & 1 \\
31 & 1553 & SAHRUL RAMADAN & 0.8 & 0.6 & 0.6 & 0.8 & 1 \\
32 & 1554 & SARTIKA ANDRIANI & 0.6 & 0.6 & 1 & 1 & 1 \\
33 & 1555 & SHENDI IKHWANDA & 0.8 & 0.8 & 0.6 & 1 & 1 \\
34 & 1556 & SISKA & 0.8 & 0.8 & 0.6 & 1 & 1 \\
35 & 1557 & SUGIARTO & 0.6 & 0.6 & 0.6 & 1 & 1 \\
36 & 1558 & SULIS HARIANI & 0.4 & 0.4 & 0.4 & 0.6 & 1 \\
37 & 1559 & SURYA RAMADHAN & 0.8 & 0.6 & 0.6 & 0.8 & 1 \\
38 & 1560 & TRI WULAN DARI & 0.8 & 0.8 & 0.8 & 0.6 & 1 \\
39 & 1561 & ULUL AMRI & 0.8 & 0.8 & 1 & 0.8 & 1 \\
40 & 1563 & YUNITA RAMAYANI & 1 & 0.4 & 1 & 1 & 1 \\
\hline & & & \multicolumn{5}{c}{ Sumber: Data Olahan }
\end{tabular}

\subsection{Perancangan Arsitektur Jaringan Saraf Tiruan}

Jaringan yang digunakan untuk mengatahui tingkat pemahaman siswa terhadap mata pelajaran adalah Jaringan Saraf Tiruan backpropagation dengan langkah pembelajaran feedforward. Jaringan ini memiliki beberapa lapisan, yaitu lapisan masukan, lapisan keluaran dan beberapa lapisan tersembunyi. Lapisan tersembunyi tersebut membantu jaringan untuk dapat mengenali lebih banyak pola masukan dibandingkan dengan jaringan yang tidak memiliki lapisan tersembunyi. Parameter-parameter dalam pembentukan jaringan backpropagation menggunakan 4 variabel masukan, 1 lapisan tersembunyi dengan 2 dan 1 lapisan keluaran adalah sebagai berikut:

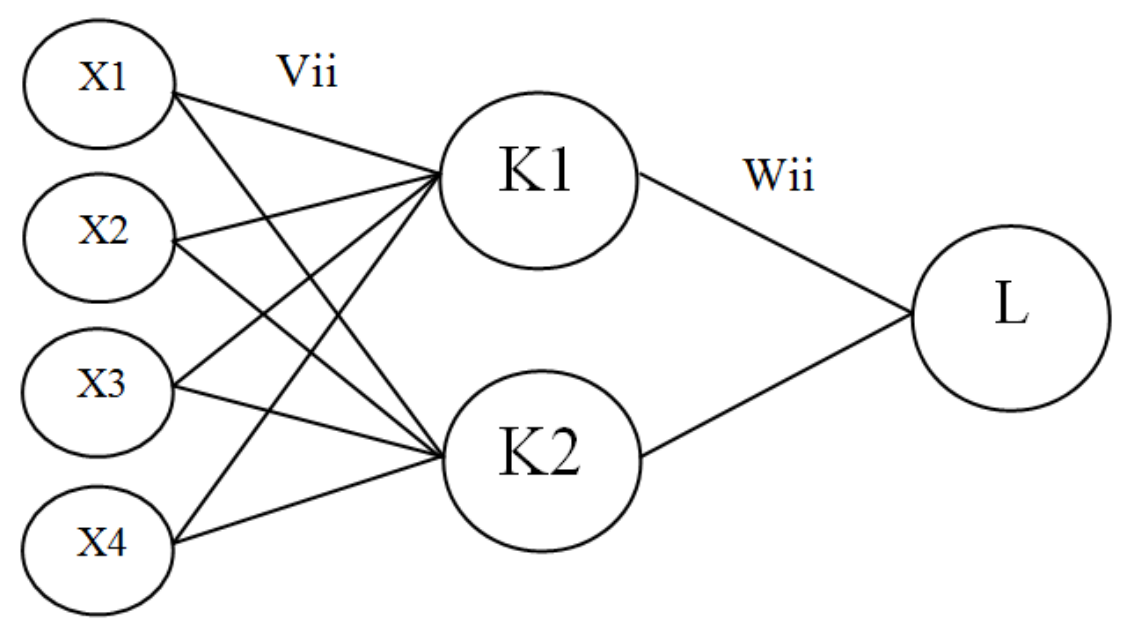

Gambar 1 Arsitektur Jaringan Saraf Tiruan Memprediksi Tingkat Pemahaman Siswa Terhadap Mata pelajaran 
Jaringan Saraf yang akan dibangun adalah algoritma propagasi balik (backpropagation) dengan fungsi aktivasi Sigmoid. Fungsi aktivasi dalam Jaringan Saraf Tiruan dipakai untuk proses perhitungan terhadap nilai aktual output pada hidden layer dan menghitung nilai aktual output pada output layer.

\subsection{Pendefinisian Output}

Hasil yang diharapkan pada tahap ini adalah deteksi pola menentukan nilai terbaik untuk tingkat pemahaman siswa tentang subjek. Hasil pengujian ada adalah sebagai berikut:

a. Untuk mengetahui tingkat pemahaman siswa tentu saja didasarkan pada kegiatan mengajar. Output dari tingkat pemahanan yaitu apakah siswa memahami terhadap mata pelajaran dengan bobot 1 .

b. Kategorisasi "memahami"

Kategori untuk "memahami" ditentukan oleh tingkat error minimum dari target "memahami" yang 1. Mereka mengkategorikan pada Tabel 4.4. sebagai berikut:

Tabel 3 Data Kategorisasi "mengerti"

\begin{tabular}{|c|l|c|}
\hline No & \multicolumn{1}{|c|}{ Keterangan } & Error Minimum \\
\hline 1 & Sangat Memahami & $0.0000-0.0010$ \\
\hline 2 & Memahami & $0.0011-0.0100$ \\
\hline 3 & Cukup Memahami & $0,0101-0,1000$ \\
\hline
\end{tabular}

\subsection{Perancangan arsitektur 4-2-1 dengan Jaringan Saraf Tiruan}

Perancangan data dengan Jaringan Saraf Tiruan untuk data pelatihan dan pengujian, maka digunakan 4 variabel input yaitu:

$\begin{array}{ll}X_{1} & =\text { Pengetahuan } \\ X_{2} & =\text { Keterampilan/Kemampuan } \\ X_{3} & =\text { Penilaian dan Beban Kerja } \\ X_{4} & =\text { Bimbingan dan Konseling }\end{array}$

Dalam perhitungan secara manual ini hanya diberikan sampel data input dari data sebagai contoh pembuktian dengan menggunakan 4 variabel input, yaitu $X_{1}, X_{2}, X_{3}, X_{4}$.

Berikut tahapan-tahapan yang akan dilakukan dalam pengguna algoritma propagasi balik dengan fungsi aktivasi sigmoid. Tahapan yang harus dilakukan adalah sebagi berikut:

1. Inisialisasi (initialization), merupakan tahap di mana variabel-variabel nilai akan diset atau didefinisikan terlebih dahulu, misalnya seperti: nilai data input, weight, nilai output yang diharapkan, learning rate dan nilai-nilai data lainnya.

2. Aktivasi (activation),merupakan proses perhitungan terhadap nilai aktual output pada hidden layer dan menghitung nilai actual output pada output layer. 
3. Weight Training, merupakan proses perhitungan nilai error gradient pada output layer dan menghitung nilai error gradient pada hidden layer

4. Iteration, merupakan tahap akhir dalam penggujian, dimana jika masih terjadi error minimum yang diharapkan belum ditemukan maka kembali pada tahap aktivasi (activation).

Dalam pelatihan ataupun pembentukan Jaringan Saraf Tiruan yang perlu dilakukan pertama kali adalah inisialisasi bobot awal. Di mana bobot awal ini akan menghubungkan simpul-simpul pada lapisan input dan juga lapisan tersembunyi (hidden layer).Bobot awal pada algoritma di atas adalah $v=(v 11, v 12, v 21, v 22, v 31$, $v 32, v 41, v 42)$, sedangkan bobot biasnya dipilih secara acak pada simpul-simpul lapisan tersembunyi (hidden layer) dan lapisan output ( w11 dan w12) dipilih secara acak.

Algoritma pelatihan backpropagation dengan menggunakan 4 input layer, 2 layer tersembunyi, 1 output layer dengan fungsi aktivasi sigmoid biner adalah sebagai berikut :

1. Tahap inisialisasi :

Tuliskan nilai input yang diberikan

$\begin{array}{rrr}X_{1} & = & 0.8 \\ X_{2} & = & 0.6 \\ X_{3} & = & 0.6 \\ X_{4} & = & 0.8 \\ \text { Target }=1 & & \text { Leraning } \operatorname{rate}(\alpha)=0.1\end{array}$

Berikan nilai bobot $(V$ ) dari input ke lapisan tersembunyi dengan nilai acak.

Tabel 4. Nilai Bobot dari Input ke Hidden Layer

\begin{tabular}{|c|c|c|}
\hline & ${ }_{1}^{K}$ & $\mathrm{~K}_{2}$ \\
\hline $\mathrm{X}_{1}$ & 0.2 & -0.3 \\
\hline $\mathrm{X}_{2}$ & 0.4 & 0.1 \\
\hline $\mathrm{X}_{3}$ & 0.3 & -0.5 \\
\hline $\mathrm{X}_{4}$ & 0.5 & -0.4 \\
\hline
\end{tabular}

Berikan nilai bobot $(W)$ dari lapisan tersembunyi ke output dengan nilai acak.

Tabel 5. Nilai Bobot dari Hidden Layer ke Output

\begin{tabular}{|c|c|}
\hline & $L$ \\
\hline$K_{1}$ & -0.3 \\
\hline$K_{2}$ & -0.2 \\
\hline
\end{tabular}

2. Tahap Aktivasi

a. Hitung keluaran tiap node (node tersembunyi dan node output)

$$
\begin{aligned}
& K 1=X_{1} \cdot V_{11+} X_{2} \cdot V_{21}+X_{3} \cdot V_{31+} X_{4} \cdot V_{41} \\
& =0,8 \cdot 0,2+0,6 \cdot 0,4+0,6 \cdot 0,3+0,8 \cdot 0,5
\end{aligned}
$$




$$
\begin{aligned}
& =0,9800 \\
& \quad=\text { Sigmoid }[0,9800]=\frac{1}{\left(1+e^{0,8400}\right)}=0 \cdot 2729 \\
& K 2=X_{1} \cdot V_{12+} X_{2} \cdot V_{22+} X_{3} \cdot V_{32+} X_{4} \cdot V_{42} \\
& =0,8 \cdot-0,3+0,6 \cdot 0,1+0,6 \cdot-0,5+0,8 \cdot-0,4 \\
& =-0,8000 \\
& =\text { Sigmoid }[-0,8000]=\frac{1}{\left(1+e^{-0,1600}\right)}=0,6900 \\
& L=K 1 \cdot W_{11+K 2 .} W_{21} \\
& =0,2729 \cdot-0 \cdot 3+0,6900+-0.2 \\
& =-0,2199 \\
& =
\end{aligned}
$$

b. Hitung nilai error output dan hidden layer

Rumus mencari error output layer:

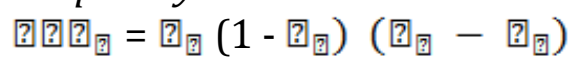

Rumus mencari error hidden layer:

$$
\text { 园圆回回 }=\text { 回 }\left(1-O_{i}\right) \quad \sum_{j} \operatorname{Err}_{j} w_{i j}
$$

$$
\begin{aligned}
\text { Err } L & =L \cdot(\alpha-L) \cdot(T-L) \\
& =0,5547 \cdot(0 \cdot 1-0,5547) \cdot(1-0,5547) \\
& =-0,1123 \\
\text { Err K1 } & =K 1 \cdot(\alpha-K 1) \cdot\left(E r r L-W_{11}\right) \\
& =0,2729 \cdot(0 \cdot 1-0,2729) \cdot(-0,1123-(-0.3)) \\
& =-0,3034 \\
\text { Err K2 } & =K 2 \cdot(\alpha-K 2) \cdot\left(E r r L-W_{21}\right) \\
& =0,6900 \cdot(0 \cdot 1-0,6900) \cdot(-0,1123-(-0.2)) \\
& =-0,0357
\end{aligned}
$$

c. Modifikasi/hitung bobot baru

Rumus memodifikasi bobot baru :

$$
W_{i j}=w_{i j}+l \cdot \operatorname{Err}_{j} \cdot O_{i}
$$

$$
\begin{aligned}
\Delta W_{11} & =W_{11}+\alpha \cdot \operatorname{Err} L \cdot K 1 \\
& =-0,3+0,1 \cdot-0,1123 \cdot 0,2729 \\
& =-0,3031 \\
\Delta W_{21} & =W_{21}+\alpha \cdot \operatorname{Err} L \cdot K 2 \\
& =-0,2+0,1 \cdot-0,1123 \cdot 0,6900 \\
& =-0,2078 \\
\Delta V_{11} & =V_{11}+\alpha \cdot \operatorname{Err} K 1 \cdot j_{1} \\
& =0,2+0,1 \cdot-0,3034 \cdot 0,8 \\
& =0,1993 \\
\Delta V_{12} & =V_{12+} \alpha \cdot \operatorname{Err} K 2 \cdot j_{1} \\
= & -0,3+0,1 \cdot-0,0357 \cdot 0,8 \\
= & -0,3029 \\
\Delta V_{21} & =V_{21+} \alpha \cdot \operatorname{Err} K 1 \cdot J_{2} \\
& =0,4+0,1 \cdot-0,3034 \cdot 0,6 \\
= & 0,3665 \\
\Delta V_{22} & =V_{22}+\alpha \cdot \operatorname{Err} K 2 \cdot J_{2}
\end{aligned}
$$




$$
\begin{aligned}
& =0,1+0,1 \cdot-0,0357 \cdot 0,6 \\
& =0,0979 \\
\Delta V_{31} & =V_{31+} \alpha \cdot \operatorname{Err} K 1 \cdot J_{3} \\
& =0,3+0,1 \cdot-0,3034 \cdot 0,6 \\
& =0,2995 \\
\Delta V_{32} & =V_{32+} \alpha \cdot \operatorname{Err} K 2 \cdot J_{3} \\
& =-0,5+0,1 \cdot-0,0357 \cdot 0,6 \\
& =-0,5021 \\
\Delta V_{41} & =V_{41+} \alpha \cdot \operatorname{Err} K 1 \cdot J_{4} \\
& =0,5+0,1 \cdot-0,3034 \cdot 0,8 \\
& =0,4993 \\
\Delta V_{42} & =V_{42+} \alpha \cdot \operatorname{Err} K 2 \cdot J_{4} \\
& =-0,4+0,1 \cdot-0,0357 \cdot 0,8 \\
& =-0,4029
\end{aligned}
$$

\subsection{Prediksi Tingkat Pemahaman Siswa Terhadap Mata Pelajaran}

Tahap terakhir adalah proses prediksi tingkat pemahaman siswa terhadap mata pelajaran. Tahapan ini dilakukan dengan membandingkan nilai error minimum dari hasil yang didapat. Dengan model arsitektur 4-5-1, data akan diprediksi untuk melihat seberapa akurat model ini dapat mengenali data. Adapun data yang akan diprediksi untuk melihat tingkat kebenaranya dapat dilihat pada tabel 6 berikut ini.

Tabel 6. Hasil Prediksi dengan Model 4-2-1

\begin{tabular}{|l|l|l|c|l|}
\hline \multicolumn{2}{|c|}{ Prediksi Model 4-2-1 } & \multicolumn{2}{c|}{ Prediksi } & \multicolumn{1}{c|}{ Ket } \\
\hline \multicolumn{1}{|c|}{ No } & \multicolumn{1}{|c|}{ NIS } & \multicolumn{1}{c|}{ Database } & JST & Hasil \\
\hline 1 & 1542 & Cukup Paham & 0.0116 & Benar \\
\hline 2 & 1544 & Cukup Paham & 0.0232 & Benar \\
\hline 3 & 1545 & Cukup Paham & 0.0502 & Benar \\
\hline 4 & 1546 & Cukup Paham & 0.0122 & Benar \\
\hline 5 & 1547 & Cukup Paham & 0.0136 & Benar \\
\hline 6 & 1548 & Cukup Paham & 0.0122 & Benar \\
\hline 7 & 1549 & Cukup Paham & 0.0442 & Benar \\
\hline 8 & 1550 & Cukup Paham & 0.0111 & Benar \\
\hline 9 & 1551 & Cukup Paham & 0.0255 & Benar \\
\hline 10 & 1552 & Tidak Paham & 0.1308 & Salah \\
\hline 11 & 1553 & Cukup Paham & 0.0126 & Benar \\
\hline 12 & 1554 & Cukup Paham & 0.0112 & Benar \\
\hline 13 & 1555 & Cukup Paham & 0.0114 & Benar \\
\hline 14 & 1556 & Cukup Paham & 0.0114 & Benar \\
\hline 15 & 1557 & Cukup Paham & 0.0232 & Benar \\
\hline 16 & 1558 & Tidak Paham & 0.4181 & Salah \\
\hline 17 & 1559 & Cukup Paham & 0.0126 & Benar \\
\hline 18 & 1560 & Cukup Paham & 0.0134 & Benar \\
\hline
\end{tabular}




\begin{tabular}{|l|l|l|c|c|}
\hline \multicolumn{2}{|c|}{ Prediksi Model 4-2-1 } & \multicolumn{2}{c|}{ Prediksi } & Ket \\
\hline \multicolumn{1}{|c|}{ No } & \multicolumn{1}{c|}{ NIS } & \multicolumn{1}{c|}{ Database } & JST & Hasil \\
\hline 19 & 1561 & Cukup Paham & 0.0112 & Benar \\
\hline 20 & 1563 & Cukup Paham & 0.0108 & Benar \\
\hline
\end{tabular}

Dari hasil prediksi yang diperoleh didapat hasil bahwa JST dapat melakukan prediksi diatas $90 \%$ tingkat akurasi kebenaranya.

\section{KESIMPULAN}

Berdasarkan hasil dan pembahasan diatas, maka penulis dapat mengambil kesimpulan sebagai berikut :

1. Menambahkan banyak hidden layer pada saat pelatihan dan pengujian, bukan merupakan suatu hasil yang maksimal. Untuk 5 model arsitektur yang dirancang, 4-2-1 adalah model yang memiliki tingkat MSE pelatihan terbesar yaitu 0.0108

2. Setelah dilakukan percobaan dalam proses pelatihan dan pengujian sistem yang dilakukan dengan menggunakan software aplikasi Matlab 6.1. Model Jaringan Syaraf Tiruan yang digunakan adalah 4-2-1, model 4-3-1, model 4-4-1, model 45-1 dan model 4-6-1, dapat diperoleh hasil yang baik dengan melihat MSE Pelatihan yang terkecil adalah 4-2-1.

3. Dengan model arsitektur 4-2-1, dapat melakukan prediksi tingkat pemahaman siswa terhadap mata pelajaran dengan menunjukkan performa diatas $90 \%$.

\section{DAFTAR PUSTAKA}

[1] Yani, E. Nurul M. Sukarno," Perancangan Dan Implementasi Jaringan Saraf Tiruan Backpropagation Untuk Mendiagnosa Penyakit Kulit",2005.

[2] Maharani D. Wuryandari. Aji Sudarsono, "Jaringan Syaraf Tiruan Untuk Memprediksi Laju Pertumbuhan Penduduk Menggunakan Metode Bacpropagation (Studi Kasus Di Kota Bengkulu)", Bengkulu,2016.

[3] Agus Perdana Windarto, "Implementation of Neural Networks in Predicting the Understanding Level of Students Subject," Int. J. Softw. Eng. Its Appl., vol. 10, no. 10, pp. 189-204, 2016.

[4] McCarthy, M. Dahria," Jurnal SAINTIKOM. LPM STMIK TRI GUNA DARMA. Sumatera Utara", Medan, 2008.

[5] Maria Agustin," Penggunaan Jaringan Syaraf Tiruan Backpropagation Untuk Seleksi Penerimaan Mahasiswa Baru Pada Jurusan Teknik Komputer Di Politeknik Negeri Sriwijaya", Semarang,2012

[6] Simon Haykin, Irma Handayani,". Peramalan Beban Tenaga Listrik Jangka Pendek Menggunakan Metode Jaringan Syaraf Tiruan", Banten,2012. 